\title{
Experimental insight on the role of forced flow velocity and separation distance on reverse smoldering
}

\begin{abstract}
Smoldering processes occurring in nature is accompanied by the presence of air which affects the regression rates. Smoldering accompanied by air is the leading cause of deaths in residential fires and a source of safety concerns in commercial aircrafts. One aspect which has not been addressed in the field of smoldering combustion is the way the smoldering regression rates are affected by the presence of forced air. The work attempts to synthesize a comprehensive view of smoldering combustion accompanied by varying air flow at selected velocities. The separation distance between the external source and the fuel, velocity of the flow and the surface orientation of fuel are the key controlling parameters investigated in this work. The investigation is carried out with the aid of an experimental setup with incense sticks as pilot fuel. Results state that, variable forced flow has significant effects on the smoldering process. The extent of the effect varies for different controlling parameters. This study will be helpful in determining the time required to control the smoldering combustion process which is the reason behind most of the fires including the on-flight fires in aircrafts.
\end{abstract}

Volume 2 Issue $6-2018$

\author{
Rakshantha M, Bunny Venkat Y,Vinayak \\ Malhotra \\ Department of Aerospace Engineering, SRM Institute of Science \\ and Technology, India
}

\begin{abstract}
Correspondence: Vinayak Malhotra, Department of Aerospace Engineering, SRM Institute of Science and Technology, India,Tel+9I-9840599069, Email vim99@gmail.com
\end{abstract}

Received: July 05, 2018 | Published: November 30, 2018

Keywords: combustion, reverse smoldering, forced flow, separation distance, orientation, regression rate

\section{Introduction}

Smoldering is a slow combustion process that burns without flame and leads to the initiation of fire. Smoldering is the main responsible potential source of substantial fire hazards generating momentous loss of nature, resources, economy, and fire deaths. Smoldering combustion can be initiated by weak sources of heat and yields a high conversion of fuel to toxic products per unit mass smoldered, can shortly cause transition to flaming combustion and difficult to detect and extinguish. The important attribute of smoldering is that it is difficult to detect and extinguish and it can abruptly transit to flaming. Smoldering fires have resulted in significant operational and functional engineering failures reported on earth and as well as in space operations. The smoldering is often described as a heterogeneous combustion, because the reaction occurs on the surface of the solid fuel, rather than in the gaseous phase of the released flammable vapors. It is a combination of partial combustion and pyrolysis. The propagation of smoldering ignition front is well known to develop in three different zones viz., degradation, smoldering reaction and ash. Smoldering combustion is broadly studied and defined according to the direction in which the smolder reaction propagates relative to the oxidizer flow viz., reverse and forward (Figure 1). In forward smoldering, the air moves in the same direction as the smoldering front whereas in reverse smoldering, the air moves in the opposite direction of the smoldering front. An important aspect in attention is the existence of air flow at certain velocities (forced flow) in combustion processes. The presence of external forced flow over the combustion processes is very likely to affect the ignition and the process propagation. The altered ignition possibly will result in smoldering yielding a higher conversion of fuel to toxic compounds than does flaming and may undergo a transition to flaming.

Following the classical work of Palmer' on 'Smoldering Combustion in Dusts and Fibrous Materials', appreciable experimental, numerical, analytical work had been done contributing towards the scientific advancement. Kinbara et al., ${ }^{2}$ experimented on the downward propagation of smoldering combustion through solid materials. The velocity of propagation of smoldering downward through vertical samples was studied for the cases of (a) circular rods of rolled paper, (b) circular incense sticks, (c) strips of cardboard, and (d) piles of cardboard tightly bound with thread. The velocity perpendicular to the fire front was observed in a chamber of temperature. Based on the results, the theory was proposed encompassing that the heat produced by the combustion of a solid body per unit time is proportional to the rate of air supplied by diffusion proportional to the temperature gradient. The heat was denoted to be inversely proportional to the temperature difference and there exists a stagnant layer of combustion gases covering the surface of the solid, and both the fresh-air supply and heat dissipation from the solid into the air take place at the surface of this layer.

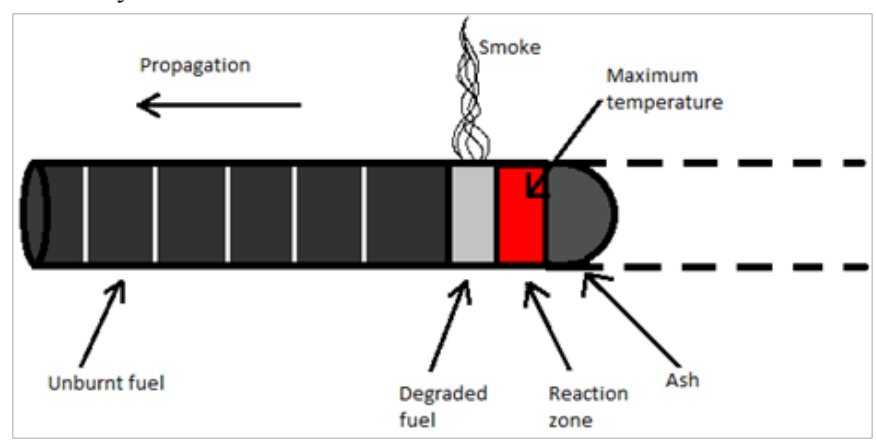

Figure 1 Schematic of smoldering with different zones and the direction of propagation.

Moussa et al., ${ }^{3}$ presented a coordinated theoretical and experimental investigation of the mechanism of smoldering in materials. Both steady 
and transient smoldering was observed for single cylindrical cellulosic elements, mounted horizontally in quiescent oxygen environments of varying pressures and compositions. An extinguishment limit, separating the steady from transient regions, was observed at welldefined combinations of oxygen mole fraction and partial pressure. In the region of steady smoldering, the measured propagation speed and maximum temperature in the smoldering zone was noted to depend on the oxygen partial pressure and mole fraction in the environment However, independent of the environmental conditions, the speed was observed to be uniquely related to the maximum temperature. It was postulated that cellulose, upon heating, decomposes to yield char and volatiles. The char then reacts with oxygen, diffusing from the surroundings, to provide the heat flux needed to sustain pyrolysis. Based on the mechanism, the predicted characteristics of steady smoldering and of the extinguishment limit were found to be in good agreement with the experimental results. Ohlemiller \& Lucca $^{4}$ investigated experimental comparison of forward and reverse smolder propagation. Two types of permeable fuels were examined, a cellulosic loose fill insulation (wood fibers) and a particulate polymer material (polyisocyanurate). Air flow velocity was varied with thermocouples and gas sampling $\left(\mathrm{O}_{2}, \mathrm{CO}, \mathrm{CO}_{2}\right)$ utilized to probe the structure of the two types of smolder wave. Results stated that there are marked qualitative and quantitative differences in the two smolder propagation modes. Reverse smolder quickly reaches a steady propagation rate determined largely by heat transfer processes whereas, forward smolder propagation is unsteady and moves at a lower rate that appears limited by the stoichiometry of char oxidation.

Both modes of propagation are ultimately limited by the rate of oxygen supply. Ohlemiller ${ }^{5}$ reviewed the smoldering combustion of various natural and synthetic solid materials constituting substantial fire hazard. The review focused on the coupled chemical and physical processes involved in self-sustained propagation of smoldering. The potential heat sources (gas-phase oxidation, oxidative polymer degradation. char oxidation) were examined, along with the heat sinks (polymer pyrolysis, water vaporization). It was concluded that, even for the most-studied case of cellulose, the chemical mechanisms involved in these processes are both too complex and too poorly understood to be included in a smolder propagation model. Existing smolder propagation models in the literature were reviewed and all represent great simplifications of the general case and none closely describes a realistic smoldering fire hazard. A general model of the Thermophysics of propagation was presented as a benchmark against which to compare existing models. It was reinstated that the truly useful predictive models of realistic hazard situations remain to be developed.

Jones \& Wake $^{6}$ explored activation energies measurement of ignition of a wide variety of solid materials of practical importance. The Frank-Kamenetskii model of thermal ignition was used in their determination. Comments were made on the values in terms of the nature of the respective materials and in terms of the value of the measured quantities as input to mathematical simulation of ignition. Richard et al., ${ }^{7}$ assessed the potential health hazards associated with contaminant exposure in the extended spaceflight environment on long duration missions. NASA reported to have identified many on-board contaminants during previous spaceflights. NASA established the Center for Space Environmental Health (CSEH) in 1990 and as part of its mission. CSEH evaluated existing knowledge and approaches to risk assessment in the context of space environmental health and identified the research needs that were important for characterizing and predicting human risk associated with chemical exposure in the extended spaceflight environment. These were organized into three major categories: I. Identification of contaminants and contaminant sources; II. Identification of target organ/systems that may exhibit increased susceptibility to toxic insult as a result of physiologic alterations experienced in the extended spaceflight environment; and III. Application of risk assessment/characterization to the spaceflight environment. Schult et al., ${ }^{8}$ utilized preceding experimental results that for opposed flow smolder, decomposition of the solid fuel into char is the chemical process which drives the smolder process. They modeled the decomposition as a one-step reaction. The model suggested that extinction occurs when decomposition is complete.

Large activation energy asymptotic methods were employed to find uniformly propagating, planar smolder wave solutions. The characteristics viz., propagation velocity, burning temperature, final degree of fuel decomposition, and extinction limits were determined along with the spatial profiles of gas flux, oxidizer concentration, temperature, and degree of decomposition of the solid. The work was further extended to the assessment of porous cylindrical samples closed to the surrounding environment except at the ends, with gas forced into the sample through one of the ends. ${ }^{9}$ The smolder wave solutions were interpolated with two different structures. Each structure was stated to have two interior layers. One layer is that of the combustion reaction, while the other is due to heat transfer between the solid and the gas. It was noted that the layers propagate with constant velocity and are separated by a region of constant high temperature. Results promoted that a so-called reaction leading wave structure occurs when the velocity of the combustion layer exceeds that of the heat transfer layer, while a so-called reaction trailing wave structure was obtained when the combustion layer is slower than the heat transfer layer. Reaction trailing structures allowed for the possibility of quenching if the gas mass influx is large enough. For each wave structure there exist stoichiometric and kinetically controlled solutions in which the smolder velocity is determined, by the rate of oxygen supply to the reaction site and by the rate of consumption in the reaction, i.e., by the kinetic rate. Stoichiometric (kinetically controlled) solutions occurred when the incoming gas flux is sufficiently low (high). For each of the four solution types, an analytical expression for the propagation velocities of the two layers, the burning temperature, and the final degree of solid conversion was determined. Gravitational forces were considered and shown to have a minimal effect provided the ambient pressure is large compared to the hydrostatic pressure drop. The solutions obtained provided qualitative theoretical descriptions of various experimental observations of forward smolder.

Leach et al., ${ }^{10}$ presented the results from a one-dimensional transient model of forward smoldering. Fuel oxidation and pyrolysis reactions as well as a char oxidation reaction were included in the model. The solid energy, solid species, gas energy, oxygen species (bulk gas and surface), and overall mass conservation equations were discretized in space using finite-difference techniques and were solved using VODE, an ordinary differential equation integrator designed for stiff equations. Local thermal and chemical nonequilibrium were allowed in the model and transfer coefficients were derived from a Nusselt number correlation. A base case was chosen to represent experimental conditions reported in the literature. The effects of inlet gas velocity, kinetic frequency factors, inlet oxygen concentration, and fuel properties such as specific heat, density, conductivity, and pore diameter were studied. Bar-llan et al., ${ }^{11}$ conducted smolder tests on polyurethane foam using air as oxidizer aboard the NASA Space 
Shuttle (STS-105 and STS-108 missions) on forward forced-flow. The two tests provided the only significant forward smolder data in microgravity. A complimentary series of ground-based tests were also conducted to determine, by comparison with the microgravity data, the effect of gravity on the forward smolder propagation. The objective of the study was to provide a better understanding of the controlling mechanisms of smolder for the purpose of control and prevention, both in normal and microgravity. The data consisted of temperature histories from thermocouples placed at various axial locations along the fuel sample centerline, and of permeability histories obtained from ultrasonic transducer pairs also located at various axial positions in the fuel sample.

A comparison of the tests conducted in normal and microgravity indicated that the smolder propagation velocities were higher in microgravity than in normal gravity, and that there was a greater tendency for a transition to flame in microgravity than in normal gravity. This was attributed primarily to the reduced heat losses in the microgravity environment, leading to increased char oxidation. This observation was confirmed through a simplified one-dimensional model of the forward smolder propagation. The finding had important implications from the point of view of fire safety in a space-based environment, since smolder can often occur in the forward mode and potentially lead to a smolder-initiated fire. Rein et al., ${ }^{12}$ presented a novel computational model of smoldering combustion capable of predicting both forward and opposed propagation is developed. This was accomplished by considering the one-dimensional, transient, governing equations for smoldering combustion in a porous fuel accounting for improved chemical kinetics. The heterogeneous chemistry was modeled with a 5-step mechanism for polyurethane foam. The kinetic parameters for the mechanism were obtained from thermogravimetric data in the literature and reported by the authors elsewhere. The results from previously conducted microgravity experiments with flexible polyurethane foam were used for calibration and testing of the numerical results. Both forward and opposed smoldering configurations were examined. By considering the 5-step mechanism, the numerical model could predict qualitatively and quantitatively the smoldering behavior, reproducing the most important features of the process. Specifically, the model predicts the transient temperature profiles, the overall structure of the reactionfront, the onset of smoldering ignition, and the propagation rate.

The fact that it was possible to predict the experimental observations in both opposed and forward propagation with a single model was a significant improvement in the development of numerical models of smoldering combustion. Rein ${ }^{13}$ assessed smoldering combustion phenomenon in the form of safety and environmental hazards. The work attempted to synthesize a comprehensive view of smoldering combustion bringing together contributions from diverse scientific disciplines. The terms filtering combustion, smoking problem, deep seated fires, hidden fires, peat or peatlands fires, lagging fires, low oxygen combustion, in-situ combustion, fireflood and underground gasification, all refer to smouldering combustion phenomena. The work considered critical cases of smoldering being the leading cause of deaths in residential fires and a source of safety concerns in space and commercial flights, smouldering wildfires destroying large amounts of biomass and causing great damage to the soil, contributing significantly to atmospheric pollutant and greenhouse gas emissions. The work advocated worthy consideration of the novel environmental and energy technologies being developed based on the direct application of smouldering combustion. These included the remediation of contaminated soils, production of biochar for long term storage of carbon, enchanted oil extraction from reservoirs and gasification of coal seams. The work noted that the prospect of new opportunities for science and engineering in smoldering combustion are noticeable, but a much larger international research effort was required to increase the number of multidisciplinary experimental, theoretical and field studies.

Hagen ${ }^{14}$ investigated the effects of density, heatflux and boundary conditions on smoldering. Two focus areas were chosen: the onset of smoldering and the transition from smoldering to flaming fire. Experiments were carried out using cotton batting to study smoldering combustion. Five densities were investigated viz., 20, $40,60,80$ and $100 \mathrm{~kg} / \mathrm{m}^{3}$, with six heat flux scenarios and two sets of boundary conditions. Results indicated that density affects the onset of smoldering. Samples with high density had lower ignition temperature than samples with lower densities. It was also shown that heat flux has an impact on the onset of smoldering, but not on the smoldering process as such. Two boundary conditions were tested with four densities viz., $20,60,80$ and $100 \mathrm{~kg} / \mathrm{m}^{3}$. It was observed that a solid boundary (a wall) along one of the vertical sample sides leads to reduced smoldering velocity locally, probably as a result of more restricted oxygen transport into the sample. Smoldering velocities that differ spatially make it possible for smoldering and secondary char oxidation to coexist in the sample. The smoldering produces gaseous fuel and the secondary char oxidation ignites the gas, leading to flaming combustion. Yang et al., ${ }^{15}$ investigated the forced forward smoldering mechanism of foam by a transient one-dimensional numerical model. A three-step reaction scheme, including foam oxidation and pyrolysis, char oxidation was adopted. Based on the first principles of mass, momentum, and energy, the mass fractions of solid and gas species as well as temperature evolutions in selfpropagation regime were examined. Foam oxidation and pyrolysis fronts were found to be ahead of char oxidation front where oxygen is not completely consumed.

The critical kinetic parameters for self-sustained smoldering were determined. It was found that pyrolysis endothermic reaction, heat losses, and limited kinetics of char oxidation are favorable for smoldering extinction. Especially, smoldering extinction is more sensitive to kinetic parameters of char oxidation reaction than that of other two reactions. The halfway quenching of smoldering was noted mainly due to the weakening of char oxidation reaction, which cannot offset the pyrolysis endothermicity and heat loss to environment. In recently, Tiwari et al., ${ }^{16}$ detailed the expression to gain physical insight into the acoustic-thermal energy interaction and related implications on smoldering combustion. Thorough experiments were carried on incense stick with systematic variation of surface orientation and interspace distance between the sound source and fuel for a fixed frequency sound.

The acoustic effect was observed and evaluated with variation in fuel regression rates under diverse conditions. It was observed that the change due to acoustics followed similar trend as without with upward and downward spread undergoing maximum effect. The thermoacoustics interaction significantly increased the forward heat transfer with varying source separation distance. The maximum acoustic effect was found to occur at an intermediate sound source location whereas; the minimum effect was evaluated to occur with nearby placement of sound source. Two distinct zones were established based on external sound source location indicating no 
effect and drastic rise for upward and downward spread. Significant research contributions have escalated the fundamental understanding of the smoldering phenomenon with varying aspects and approaches. However, the heterogenous nature of the heat and mass transfer has prevented a thorough understanding. Present work is motivated by the need to have better fire safety through resourceful understanding of the smoldering singularity. One aspect which is yet to thoroughly explore is the aspect of external energy source with varying flow conditions. The presence of external varying flow source represents a resonation with physical occurrences viz., forest fires. The exposure of varying flow under diverse conditions is likely to alter the regression rates through induced changes in the localized temperature and velocity fields thus affecting pyrolysis. The increase or decrease of regression rate can have significant effects and applications in engineering background. The work explores the implications of external flow velocity variation effects on smoldering spread in view of prevention and efficient utilization. The specific objectives of the study are:

a. To study the varying forced flow effects on the reverse smoldering.

b. To understand the role of key controlling parameters.

\section{Experimental setupand solution methodology}

An experimental setup was upraised for the present study (Figure 2 and Figure 3A). The experiments were systematically carried out in a quiescent room under normal gravity conditions. The experimental setup consisted of (a) hard thermocol with protractor fixed on it and firmly supported in front of a table (Figure 3B), (b) incense sticks as fuel, (c) (Figure 3C) homebased fan for variable flow (Figure 3D). The solid fuel assembly comprised of dried incense sticks $(5 \mathrm{~cm} \times 0.20 \mathrm{~cm})$ in specification and contained sawdust $(30 \%)$, charcoal $(30 \%)$ and cow dung (38.5\%) and incense chemical (1.5\%).

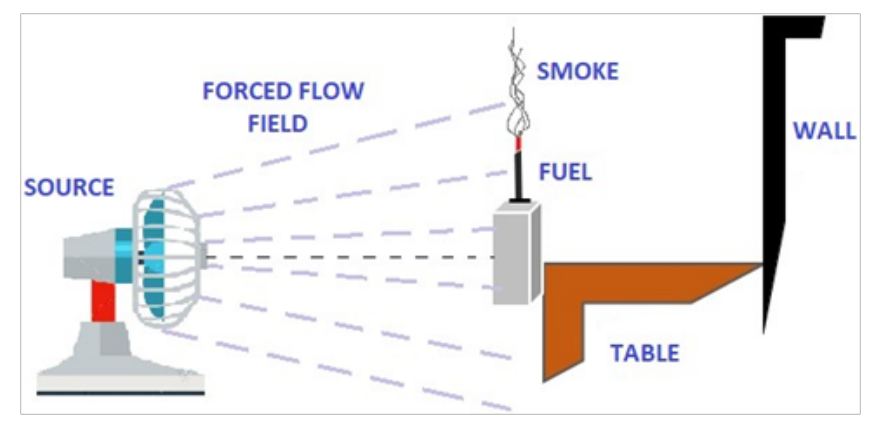

Figure 2 Schematic of the complete experimental setup.

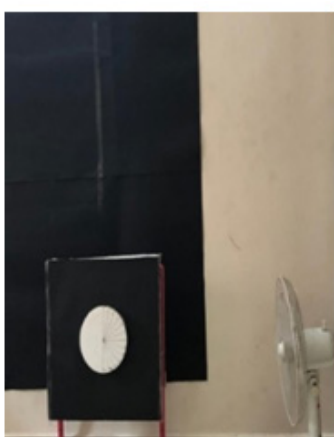

(A)

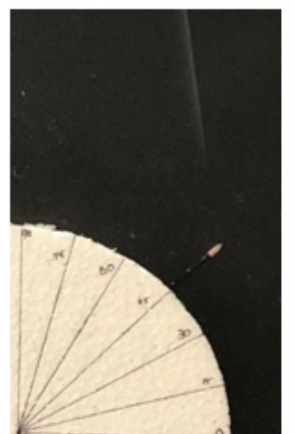

(B)

The incense sticks were selected as potential fuel because of easy availability and dried prior to experimentation to remove the moisture which can affect ignition and front spread rate. Every fuel strip was cut at the top and a spread length of $0.5 \mathrm{~cm}$ was provided to enable uniform horizontal ignition across the width. The fuel strips were marked at regular intervals of $1 \mathrm{~cm}$ to track the smoldering front propagation with time. Fuel specimen strips were ignited manually by exposing it to a pilot flame. An optical setup was made to obtain shadowgraph of the propagating front. Dark sheets were used for flow visualization to capture the smoke pattern. The forced air flow effect was generated with a homebased fan for 3 different speed levels viz., $4 \mathrm{~m} / \mathrm{s}, 4.5 \mathrm{~m} / \mathrm{s}$, $5 \mathrm{~m} / \mathrm{s}$ (measured at the surface of the fan) and suitable for experimental setup to withstand without being affected by the vibrational field. The external flow source was placed at 4 selected locations viz., $100 \mathrm{~cm}$, $75 \mathrm{~cm}, 50 \mathrm{~cm}, 30 \mathrm{~cm}$ (the closest distance possible for the setup created) with respect to the fuel orientations. Stopwatch was used to measure the split times across the marker and entire experimentation was video graphed. Every experiment was carried out within 5 minutes to bring room atmosphere back to normalcy. The regression rate $(r)$ is estimated using linear method as:

$$
r=\frac{l_{s}}{t_{a v}}(1)
$$

where, " $l_{s}$ " is average length of fuel (here, $1 \mathrm{~cm}$ ) and " ${ }_{a v}$ " is the average time taken for all marked distances. From classical theory of ignition spread, assuming unity width of fuel the regression rate $(r)$ is defined by energy balance as:

$$
r=\frac{\int q_{\text {net }}}{\rho_{s} \tau_{s} c_{s}\left(T_{\text {surface }}-T_{a}\right)}
$$

Where, " $\int q_{\text {net }}$ " is net integrated heat transfer per unit time per unit area to the unburnt fuel (forward heat transfer), " $c_{s}$ " is Solid-phase specific heat, " $\tau_{s}$ " is Solid fuel thickness, " $\rho_{s}$ " is Solid fuel density, " $T_{\text {Surface }}$ " is Surface temperature, " $T_{a}$ " is Ambient temperature. Ignition is primarily transition from a non-reactive material decomposition to a self-sustained reactive combustion. This transition is owing to an imbalance between the heat production and heat loss which relates to the energy stored in a volume as:

$$
E_{\text {net }}=E_{\text {gen }}-E_{\text {loss }}
$$

Where, " $E_{\text {net }}$ " represents the net stored energy, " $E_{\text {gen }}$ " represents the energy generated and " $E_{\text {loss }}$ " represents the energy loss. The energy production is based on an Arrhenius approximation as:

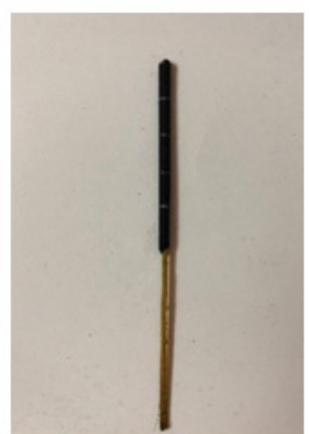

(C)

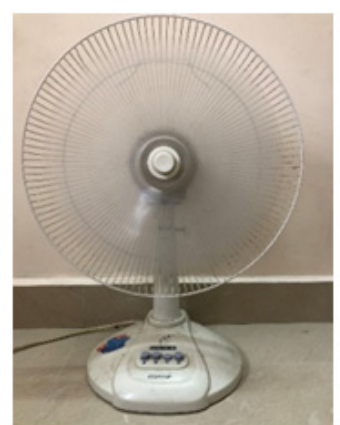

(D)

Figure 3 Pictorial view of (A) complete experimental setup (B) reverse smoldering over a thin solid fuel (C) marked incense stick (D) fan. 


$$
\begin{gathered}
\rho_{s} c_{s} V \frac{d T}{d t}=q_{P}-q_{L}(4) \\
q_{P}=\Delta H_{c} V C r e^{-\frac{E_{a}}{R T}}
\end{gathered}
$$

The associated heat energy loss is taken by assuming constant concentration of reactants in the volume (material not consumed prior to ignition) (' $\mathrm{Cr}$ ') indicating a uniform temperature.

$$
q_{L}=h A\left(T-T_{a}\right)(6)
$$

Where, " $q_{p}$ " is the Energy production $\left(=E_{g e n}\right)$, “ $q_{L}$ " represents Energy loss $\left(=E_{\text {Loss }}\right)$, " $V$ " is the volume, " $T$ " is the temperature and " $t$ " represents time, " $\Delta H_{C}$ " is the heat of combustion, " $\mathrm{Cr}$ " represents the Concentration of reactants, " $A$ " " is the Pre-exponential factor, " $E_{a}$ " is the Activation energy, " $R$ " is the Universal gas constant., " $h$ " is the convection factor.

It is important to note that the external flow velocity over the fuel is the same at all the surface orientations and all the readings presented here, represent repeatability of the order three.

\section{Results and discussions}

The experimental simulations were carried out in ambient atmosphere with $21 \%$ oxygen concentration. An experimental investigation was carried out to understand the role of varying airflow effect on the reverse smoldering process. The reverse smoldering front was analyzed for varying surface orientation $\left(0^{\circ}-90^{\circ}\right)$ with systematic variation of $15^{\circ}$ viz., $0^{\circ}, 15^{\circ}, 30^{\circ}, 45^{\circ}, 60^{\circ}, 75^{\circ}, 90^{\circ}$. The external forced flow effect was investigated by keeping the source at selected locations of $100 \mathrm{~cm}, 75 \mathrm{~cm}, 50 \mathrm{~cm}$ and $30 \mathrm{~cm}$. The forced flow velocity for different source locations were varied for the cases of $4 \mathrm{~m} / \mathrm{s}, 4.5 \mathrm{~m} / \mathrm{s}$, and $5 \mathrm{~m} / \mathrm{s}$. According to the classical heat transfer theory over thin solid fuels, the propagating front spreads by the heat feedback (forward heat transfer) from the burning to the unburnt solid fuel upstream. The extent of heat feedback is reflected in regression rates (equation 2). Prior to the main study, experimental predictions were corroborated with the well-established smoldering studies by Tiwari et al. ${ }^{16}$ The effect of surface orientation on regression rates for reverse mode was assessed without external influence. Figure 4 shows the pictorial interpretation for selected orientation cases for the base case. The regression rate variation with surface orientation without external influence was taken as the base case and utilized to compare the results for forced flow cases. The base experimentation accentuates significant change in the smoldering with the variation in governing parameters.

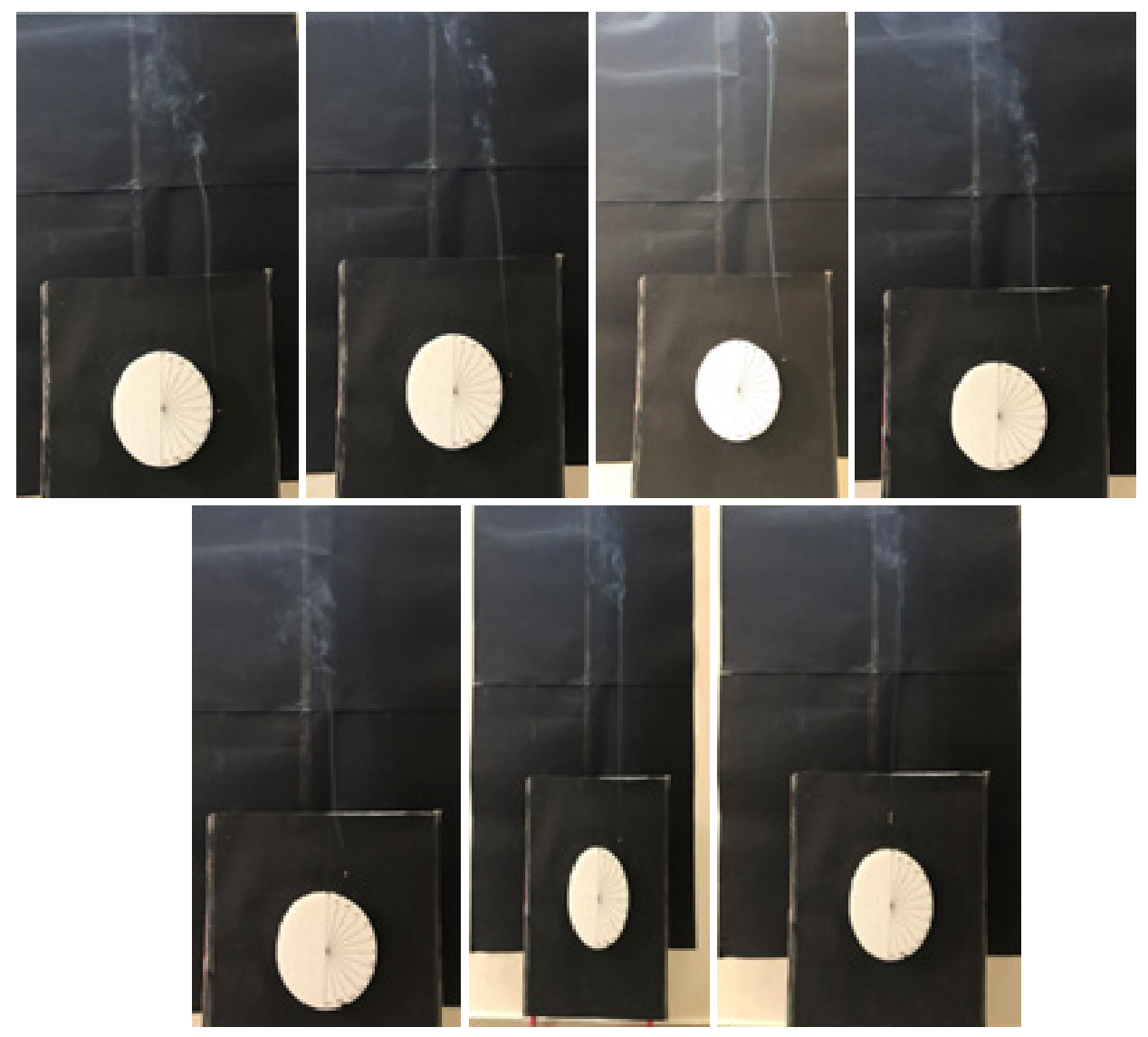

Figure 4 Pictorial view of reverse smoldering at selected orientations for source location $(100 \mathrm{~cm})$. 
Figure 5A shows the regression rate variation with surface orientation for reverse smoldering case without any external flow assistance. At horizontal orientation, the buoyant velocity on the unburnt fuel surface is zero resulting in regression rates purely to be a product of conduction heat transfer to the unburnt fuel and ash. For vertical surface orientation, the heat transfer to the unburnt fuel is still primarily owing to conduction but the ash is in convective environment with high temperature buoyant smoke moving upward across it and reducing heat loss to the surroundings. The regression rates are nearly same for both the horizontal and vertical orientations due to lower heat loss from ash to surrounding resulting in reduced heat loss from smoldering to ash. As the orientation surface orientation increases, the effect increases and reaches a peak value at an inclination of $45^{\circ}$ representing minimum heat loss case for reverse smoldering and both conduction and convection phenomenon comes together resulting in decrease of time taken to burn. With further increase in orientation, the conduction effect drops owing to buoyant smoke deviating upward and not heating the ash resulting in non-monotonic variation till vertical orientation. High regression rates can be attributed because of heightened cumulative heat transfer to the unburnt fuel. The conductive heat transfer is elevated by the presence of ash which is heated by the hot smoke. The results were validated and matched reasonably well with the preceding theories. So, the experimental setup is expected to provide a good physical understanding of the forced flow effects on reverse smoldering.

The contribution of key controlling parameters was explored in the aid of the regression rate variation. The coupled effect of external forced flow (flow velocity), location of the flow (separation distance) and surface orientation was investigated systematically in

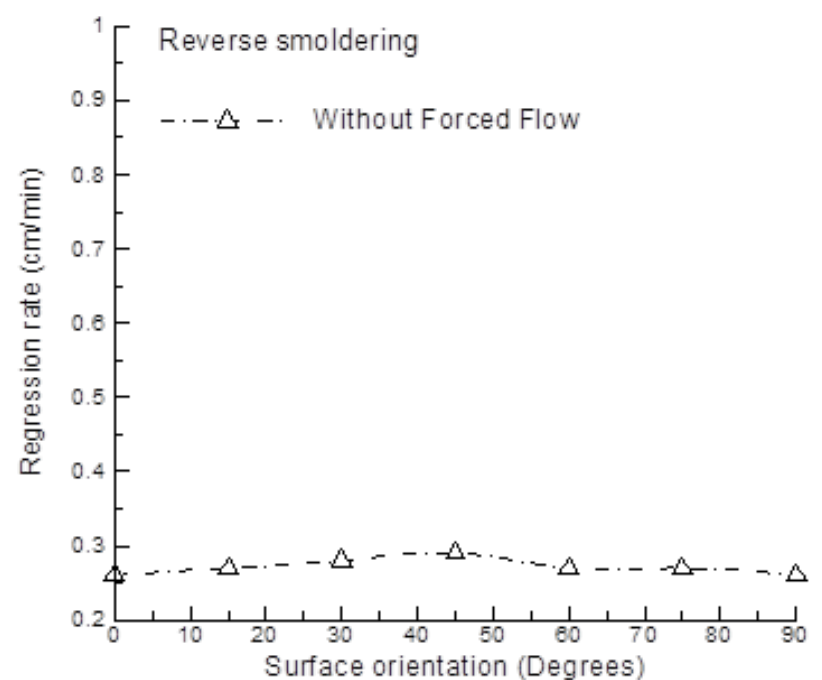

(A) the aid of fuel regression rates. First, the effect of forced flow on reverse smoldering was measured for varying surface orientation with external flow source fixed at $100 \mathrm{~cm}$ for selected varying flow velocities. Figure 5B shows the variation of regression rates with the change in orientation at three different velocities of the flow at $100 \mathrm{~cm}$ source distance. Looking at the plot, one can note that the there is a significant effect on reverse smoldering process in the presence of forced flow. The variation of regression rate values verifies the experimental prediction to sense the net energy transfer variations. The presence of external flow source results in enhanced regression rates than the base case for all flow velocities. The regression rates vary for different flow velocities but follow a monotonic reducing trend with increase in surface orientation. The maximum regression rate change was observed for horizontal surface orientation at the flow velocity of $5 \mathrm{~m} / \mathrm{s} \mathbf{1 9 2 \%}$ (rise), followed by $\mathbf{1 5 8 \%} \%$ (rise) at $4.5 \mathrm{~m} / \mathrm{s}$ and $\mathbf{1 2 7} \%$ (rise) at $4 \mathrm{~m} / \mathrm{s}$. Whereas, the least changes were noted for vertical surface orientation for $4 \mathrm{~m} / \mathrm{s}$ by $\mathbf{5 4 \%}$ (rise), followed by $\mathbf{6 5 \%}$ (rise) at $4.5 \mathrm{~m} / \mathrm{s}$ and $69 \%$ (rise) at $5 \mathrm{~m} / \mathrm{s}$ respectively. The results clearly state the dominant effect of forced flow with enhanced impact on regression rate for higher flow velocities. The gradient with $5 \mathrm{~m} / \mathrm{s}$ was noted to be higher than $4.5 \mathrm{~m} / \mathrm{s}$ and $4 \mathrm{~m} / \mathrm{s}$ for orientations till $45^{\circ}$ and the rate of change drops with further increase in surface orientation. It is interesting to note that at vertical orientation, the regression rate values falls closer for all velocities. Singularities were observed in the with close regression rate values viz., at $15^{\circ}$ and $45^{\circ}$ for flow velocities of $4 \mathrm{~m} / \mathrm{s}$ and $4.5 \mathrm{~m} / \mathrm{s}$ respectively. The change in regression rate reflects the reformed energy interaction between the ignition zone and unburnt fuel surface. Forced flow behaves as a catalyst to modify the conductive and convective heat fluxes to distinct magnitudes of energy transfer.

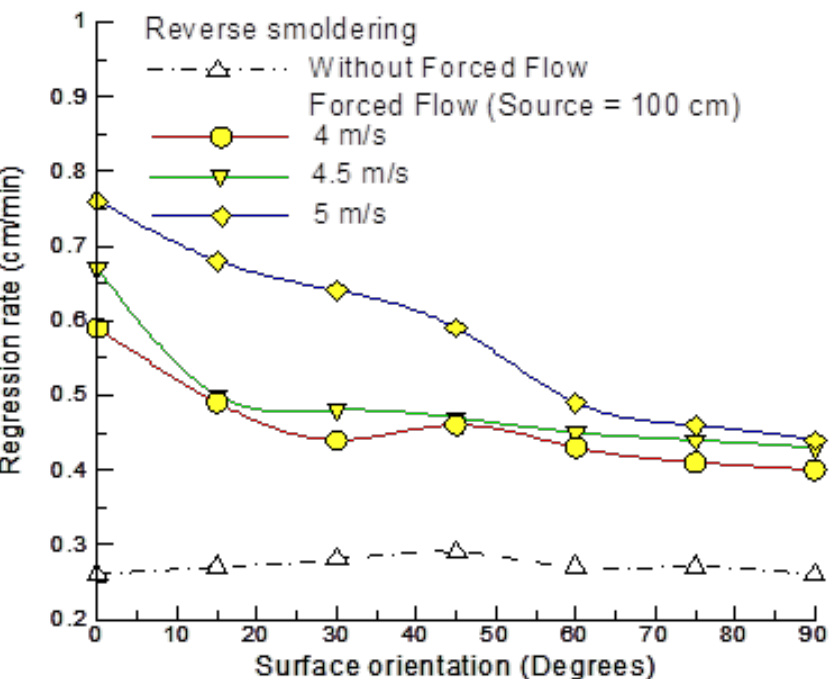

(B)

Figure $\mathbf{5}$ Variation of regression rate with surface orientation for reverse smoldering $(A)$ without forced flow (B) with forced flow.

Inferring to the results, the external flow source location was varied to understand the governing mechanism. Figure 6A shows the regression rate variation with the orientation at three different velocities with external source fixed at $75 \mathrm{~cm}$. The result shows significant rising effect on reverse smoldering process with reduced source separation distance. However, a trend dissimilar to the base $100 \mathrm{~cm}$ source location was noted. With increase in surface orientation, an increase in regression rate was noted. The experimentation establishes the very fact that forced flow enhances the smoldering rate. Quantification details that the maximum regression rate change (rise) was observed at vertical surface orientation for the flow velocity of $4.5 \mathrm{~m} / \mathrm{s}(\mathbf{1 9 6 \% )}$, followed by $188 \%$ at $5 \mathrm{~m} / \mathrm{s}$ and $162 \%$ at $4 \mathrm{~m} / \mathrm{s}$. The minimum changes (rise) were noted for horizontal surface orientation with $112 \%$ at $5 \mathrm{~m} / \mathrm{s}$ followed by $\mathbf{1 1 9 \%}$ at $4 \mathrm{~m} / \mathrm{s}$, and $\mathbf{1 4 2 \%}$ at $4.5 \mathrm{~m} / \mathrm{s}$ respectively. The investigation categorizes uniqueness of yielding regression rate values viz., at $30^{\circ}$ for all flow velocities representing similar heat transfer 
effect for varying forced flow conditions. The broader difference in the change of rate of change at varying forced flow velocities was observed at $45^{\circ}$ surface orientation. Unlike external source location $100 \mathrm{~cm}$, the reduced location of $75 \mathrm{~cm}$ represents dominance of intermediate flow velocity of $4.5 \mathrm{~m} / \mathrm{s}$ and minimum effect of maximum velocity $5 \mathrm{~m} / \mathrm{s}$. The regression rate values for $4 \mathrm{~m} / \mathrm{s}$ and $5 \mathrm{~m} / \mathrm{s}$ matches at horizontal orientation whereas, vertical orientation reflects proximity of $4 \mathrm{~m} / \mathrm{s}$ and $4.5 \mathrm{~m} / \mathrm{s}$. It is interesting to note that, no significant ash formation occurred as the velocity increases from $4 \mathrm{~m} / \mathrm{s}$ to $4.5 \mathrm{~m} / \mathrm{s}$. Though, the ash formation was substantial with the velocity increase from $4.5 \mathrm{~m} / \mathrm{s}$ to $5 \mathrm{~m} / \mathrm{s}$. With a common ground of increased regression rate for forced flow but varying trends with source location and velocities, further experimentation with reduction in external source location was carried out.

Figure $6 \mathrm{~B}$ shows the regression rate variation with surface orientation for varying forced flow conditions with external source at $50 \mathrm{~cm}$. The results highlight momentous rise with trend like source location at $100 \mathrm{~cm}$ (monotonic reduction with increase in the surface orientation from horizontal to vertical). The low velocities viz., $4 \mathrm{~m} / \mathrm{s}$ and $4.5 \mathrm{~m} / \mathrm{s}$ register momentous rise in regression rate at horizontal surface orientation whereas, for higher flow velocity of $5 \mathrm{~m} / \mathrm{s}$, the rise indicates a significant drop in rate of change. Statistically, the maximum regression rate change (rise) was observed for horizontal surface orientation at the flow velocity of $4.5 \mathrm{~m} / \mathrm{s}$ by $235 \%$, followed by $223 \%$ at $4 \mathrm{~m} / \mathrm{s}$ and $169 \%$ at $5 \mathrm{~m} / \mathrm{s}$. The minimum change (rise) was

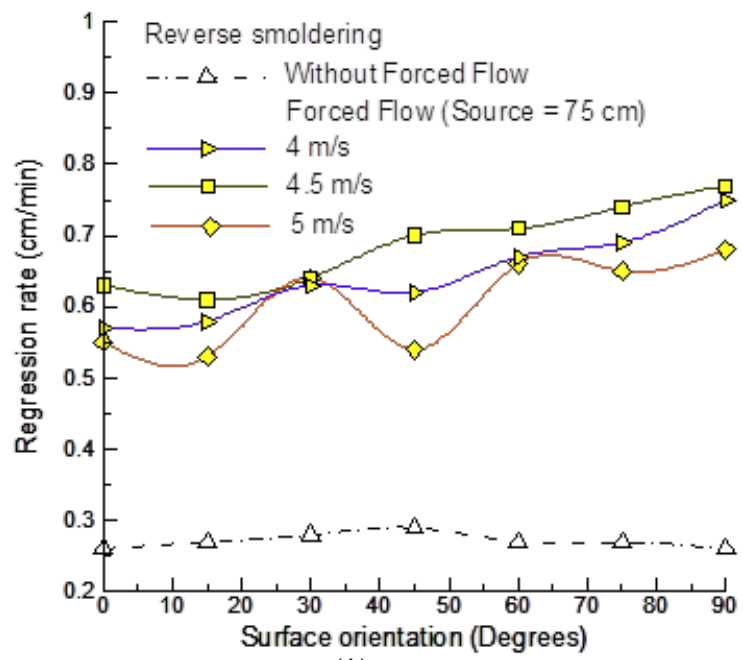

(A) noted for the vertical surface orientation at $4.5 \mathrm{~m} / \mathrm{s}$ by $\mathbf{1 0 8} \%$, followed by $112 \%$ at $4 \mathrm{~m} / \mathrm{s}$ and $142 \%$ at $5 \mathrm{~m} / \mathrm{s}$. It is interesting to note that, $4.5 \mathrm{~m} / \mathrm{s}$ and $5 \mathrm{~m} / \mathrm{s}$ flow velocities yields diverse regression rate variation with increase in surface orientation. For $4.5 \mathrm{~m} / \mathrm{s}$, highest rate of change was noted till $45^{\circ}$ and with further increase, the change in rate of change dropped to minimum. For $5 \mathrm{~m} / \mathrm{s}$ case, the regression rate variation induces reduced energy gain from horizontal surface orientation to minimum at $30^{\circ}$ and leading to gross maximum at vertical surface orientation. Following the cases of $100 \mathrm{~cm}$ and $75 \mathrm{~cm}$, for $50 \mathrm{~cm}$ source location, the regression rate values for $4 \mathrm{~m} / \mathrm{s}$ and $5 \mathrm{~m} / \mathrm{s}$ matches at $15^{\circ}$, $45^{\circ}$ and vertical surface orientation. The energy interaction reflects escalated improvements with reduced losses to provide enhanced forward heat transfer to the unburnt region reflected in improved regression rates. Further reduction in source location proves redundant and minimum feasible source location for steady reverse smoldering phenomenon was registered to be $30 \mathrm{~cm}$. At external source location of $30 \mathrm{~cm}$, higher external flow velocities viz., $4.5 \mathrm{~m} / \mathrm{s}$ and $5 \mathrm{~m} / \mathrm{s}$ results in gross blowoff phenomenon for any measurements to be conducted. The data could be taken only for the case of reduced flow velocity of $4 \mathrm{~m} / \mathrm{s}$ which restores the experimental measurements. The results provided a distinct picture of the regression rate increase with increase in flow velocity however; the increase in regression rates varies for different surface orientations at different velocities. Consequently, it is mandatory to probe the role of varying flow velocities resulting in non-linear consequences of regression rates variation.

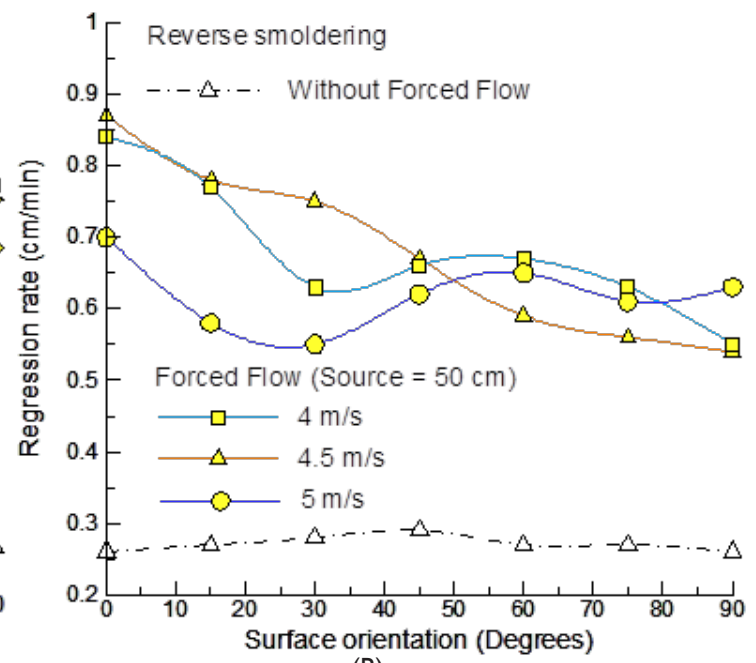

(B)

Figure 6 Variation of regression rate with surface orientation for reverse smoldering with forced flow (A) source $=75 \mathrm{~cm}(B) s 0 u r c e=50 \mathrm{~cm}$.

Next, the effect of varying forced flow velocity was examined for varying surface orientation $\left(0^{\circ}-90^{\circ}\right)$ and source distance viz., $100 \mathrm{~cm}$, $75 \mathrm{~cm}, 50 \mathrm{~cm}, 30 \mathrm{~cm}$ respectively. Figure $7 \mathrm{~A}$ shows the regression rate variation with surface orientation for fixed forced flow velocity of $4 \mathrm{~m} / \mathrm{s}$. Looking at the plot, one can note that the maximum and minimum changes in the enhanced regression rate results with different source location for different surface orientations. For horizontal orientation, the maximum regression rate was observed at $50 \mathrm{~cm}$ followed by $30 \mathrm{~cm}$ and $75 \mathrm{~cm}$. Whereas, for vertical orientation, maximum rise was noted for $75 \mathrm{~cm}$ source location followed by $30 \mathrm{~cm}$ and $50 \mathrm{~cm}$ respectively. Unlike the base case, forced flow reverse smoldering do not conforms to the pattern with maximum regression rate at intermediate surface orientation (e.g. $45^{\circ}$ ). The minimum rise for all orientations was noted for source located at $100 \mathrm{~cm}$.
It is interesting to note that, certain peculiarities of regression rate values viz., at $30^{\circ}(50 \mathrm{~cm}$ and $75 \mathrm{~cm}), 60^{\circ}(50 \mathrm{~cm}$ and $75 \mathrm{~cm})$ and $75^{\circ}$ $(30 \mathrm{~cm}$ and $50 \mathrm{~cm})$ cross over occurs representing similar heat transfer effect under varying conditions viz., the velocity of the flow, surface orientation of the fuel and the source distance. For flow velocity of $4.5 \mathrm{~m} / \mathrm{s}$ (refer Figure 7B), the horizontal surface maxima result for $50 \mathrm{~cm}$ location and minima at $100 \mathrm{~cm}$ as noted for $4 \mathrm{~m} / \mathrm{s}$. Whereas, for vertical surface orientation, the maximum rise results with source placement at $75 \mathrm{~cm}$ and minimum with source location at $100 \mathrm{~cm}$. It is interesting to note that the faraway location of location of $100 \mathrm{~cm}$ follows similar trend with varying velocities. It is important to note that at reduced source location (here, $30 \mathrm{~cm}$ ) the strong blow-off phenomenon of the reaction zone and ash formation was observed. The ignition front resulted in excessive heat loss with sudden 
extinction. Figure $7 \mathrm{C}$ indicates the variation of regression rates with surface orientation for varying external source location and fixed flow velocity of $5 \mathrm{~m} / \mathrm{s}$. Qualitatively, a trend like flow velocity of $4 \mathrm{~m} / \mathrm{s}$ can be configured. For horizontal surface orientation, the maximum regression rate rise result for $100 \mathrm{~cm}$ location and minima at $75 \mathrm{~cm}$. Whereas, for vertical surface orientation, the maximum rise results

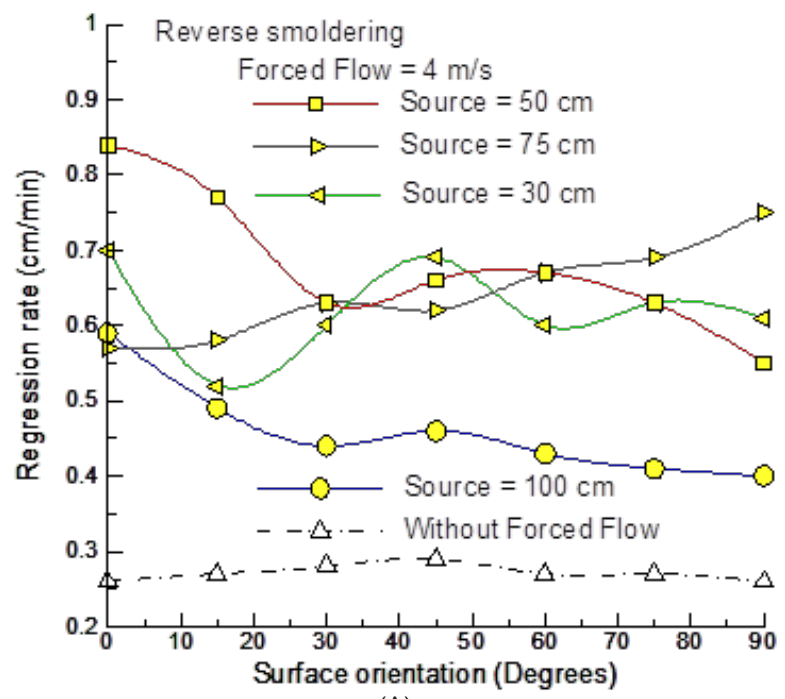

(A) with source placement at $75 \mathrm{~cm}$ and minimum with source location at $100 \mathrm{~cm}$. Special cases of regression rate values at $30^{\circ}(75 \mathrm{~cm}$ and $100 \mathrm{~cm})$ and $60^{\circ}(50 \mathrm{~cm}$ and $75 \mathrm{~cm})$ occurs signifying comparable heat transfer effects. Identical to the flow velocity of $4.5 \mathrm{~m} / \mathrm{s}$, at the source distance of $30 \mathrm{~cm}$, the reaction blow-off was observed resulting in the ignition extinction.

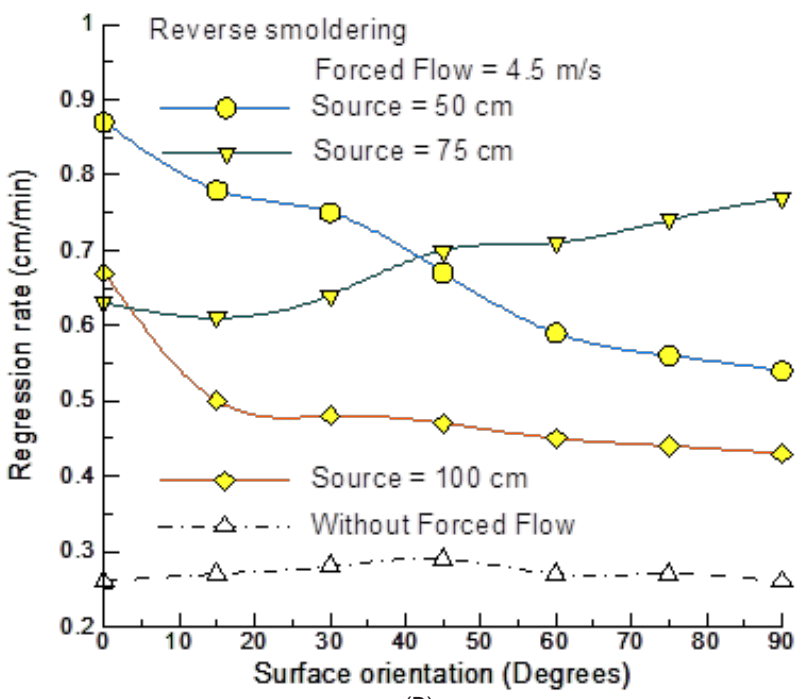

(B)

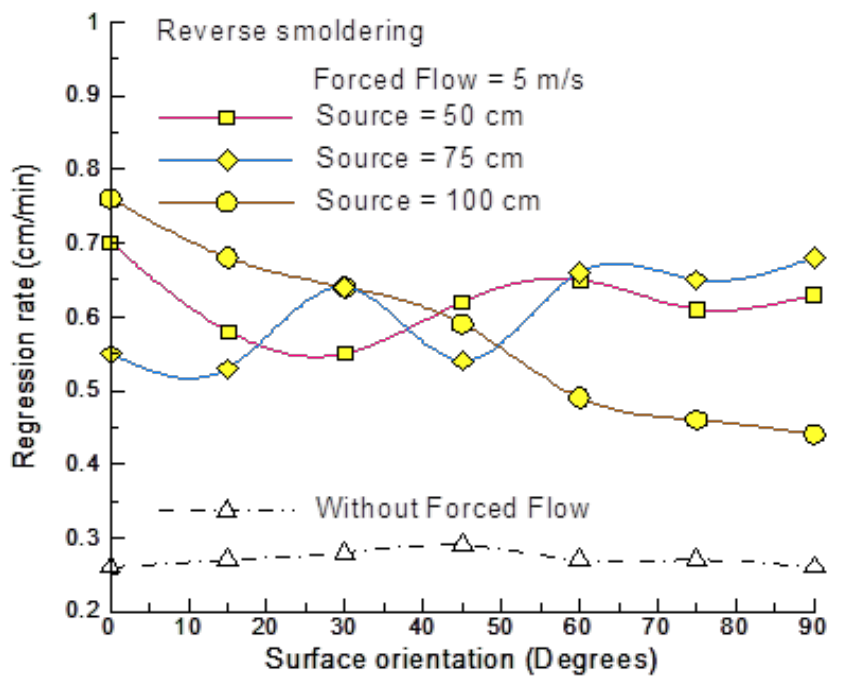

(C)

Figure 7 Effect of forced flow and fuel configuration orientation on reverse smoldering. (A) $4 \mathrm{~m} / \mathrm{s}$ (B) $4.5 \mathrm{~m} / \mathrm{s}$ (C) $5 \mathrm{~m} / \mathrm{s}$.

The governing physics for the above noted changes can be attributed to the coupled forced convection and conduction heat transfer effects on the pilot fuel. External forced flow strongly alters the convective sustenance to the fuel resulting in strong and conductive support. The enhanced conductive and convective heat transfer results in heightened energy losses under different conditions. However, the boosted regression rates are consequentially a result of enhanced forward heat transfer reflecting the higher gain than the losses. The cumulative forward energy transfer extent varies owing to the varying energy loss reflected strongly in the localized temperature and velocity flow field around the smoldering front. The nearby placement of the external flow source denotes excessive energy loss to the extinction of the ignition front.

\section{Conclusion}

An experimental investigation was carried out to identify the implications of forced flow on reverse smoldering. An experimental setup was upraised with incense stick as potential fuel. The investigation was systematically carried out for variation of flow field, external source distance, surface orientation as controlling parameters and regression rate as performance parameter. Based on the results, following conclusions can be drawn:

a) Reverse smoldering is significantly affected by the presence of an external forced flow.

b) Forced flow dominates the reverse smoldering process resulting in enhanced regression rates rise at all orientations, source 
locations and flow velocities. However, the maximum and minimum effect varies with controlled parametric variation. The forced flow reverse smoldering process do not follow the without flow trend.

c) For horizontal orientation, the maximum rise was noted as $\mathbf{2 3 5} \%$ for source located at $50 \mathrm{~cm}$, with flow velocity of $4.5 \mathrm{~m} / \mathrm{s}$ whereas, the minimum change was observed as $\mathbf{1 1 2 \%}$ for source located at $75 \mathrm{~cm}$ with flow velocity of $5 \mathrm{~m} / \mathrm{s}$.

d) For vertical surface orientation, the maximum rise was noted as $196 \%$ for source located at $50 \mathrm{~cm}$, with flow velocity of $4.5 \mathrm{~m} / \mathrm{s}$ whereas, the minimum change was observed as $\mathbf{5 4 \%}$ for source located at $100 \mathrm{~cm}$ with flow velocity of $4 \mathrm{~m} / \mathrm{s}$.

e) The increase in the flow velocity increases the convective heat transfer which enhances the coupled conductive heat transfer (reaction zone becomes larger).

f) Blow-off phenomenon was noted at all orientations for higher flow velocities (here, $4.5 \mathrm{~m} / \mathrm{s}$ and $5 \mathrm{~m} / \mathrm{s}$ ) with external heat sources placed very close to the fuel (here, $30 \mathrm{~cm}$ ).

g) The experimental predictions were validated with the conventional heat transfer theory and matches reasonably well.

h) Applications of the present work: Smoldering poses serious hazards on operational engineering systems on earth and in space. Almost all combustion processes are accompanied by the presence of air flow. Thorough understanding and utilization of forced air flow for better combustion offers an attractive alternative. Present work would be very useful for scientific, engineering, practical and functional applications involving constructive smoldering combustion and fire safety applications. The work offers seamless physical insight into forced flow effects on smoldering combustion being more harmful than the normal combustion with abrupt rise and demands proper attention and prevention. These results can be used in various terrestrial and space applications viz., to design, validate and to test engineering systems, smoldering combustion alerts, prevention from expectedly transition to fires, minimizing smoldering damages, hazards, saving life, prevention of industrial fires, building fires, residential fires, rocket fires, engine fires, forest fires and environmental pollution control.

\section{Acknowledgments}

None.

\section{Conflicts of interest}

Authors declare that there is no conflicts of interest.

\section{References}

1. Palmer KN. Smoldering Combustion in Dusts and Fibrous Materials. Combustion and Flame. 1957;1(2):129-154.
2. Kinbara T, Endo H, Sega S. Downward propagation of smoldering combustion through solid materials. Symposium (International) on Combustion. 1967;11(1):525-531.

3. Moussa NA, Toong TY, Garris CA. Mechanism of smoldering of cellulosic materials. Symposium (International) on Combustion. 1977;16(1):1447-1457.

4. Ohlemiller TJ, Lucca DA. An experimental comparison of forward and reverse smolder propagation in permeable fuel beds. Combustion and Flame. 1983;54(1-3):131-147.

5. Ohlemiller TJ. Modeling of smoldering combustion propagation. Progress in Energy and Combustion Science. 1985;11(4):277-310.

6. Jones JC, Wake GC. Measured activation-energies of ignition of solid materials. Journal of Chemical Technology and Biotechnology. 1990;48(2):209-216.

7. Richard DI, Thomas WC, Jon S, et al. Hazard identification and risk assessment in the extended spaceflight environment. Acta Astronautica. 1994;33:277-287.

8. Schult DA, Matkowsky BJ, Volpert VA, et al. Propagation and extinction of forced opposed flow smolder waves. Combustion and Flame. 1995;101(4):471-490.

9. Schult DA, Matkowsky BJ, Volpert VA, et al. Forced forward smolder combustion. Combustion and Flame. 1996;104(1-2):1-26.

10. Leach SV, Rein G, Ellzey JL, et al. Kinetic and fuel property effects on forward smoldering combustion. Combustion and Flame. 2000;120(3):346-358.

11. Bar-llan A, Rein G, Fernandez-Pello AC, et al. Forced forward smoldering experiments in microgravity. Experimental Thermal and Fluid Science. 2004;28(7):743-751.

12. Rein G, Fernandez-Pello AC, Urban DL. Computational model of forward and opposed smoldering combustion in microgravity. Proceedings of the Combustion Institute. 2007;31(2):2677-2684.

13. Rein G. Smouldering Combustion Phenomena in Science and Technology. International Review of Chemical Engineering. 2009;1:318.

14. Hagen BC. Onset of smoldering and transition to flaming fire. Dissertation for the degree of Philosophiae Doctor (PhD), Department of Physics and Technology, University of Bergen, Norway; 2013. 114 p.

15. Yang J, Chen H, Liu N. Heat Loss and Kinetic Effects on Extinction and Critical Self-Sustained Propagation of Forced Forward Smoldering. Fire Science and Technology; 2015. 831-840 p.

16. Tiwari P, Ramanan V, Malhotra V. An Experimental Insight into Thermoacoustic Smoldering. Journal of Space Exploration. 2017;6(1):119. 